\title{
Undergraduate Economics Journals: Learning By Doing
}

Robert M. Leekley, Illinois Wesleyan University, USA

Stephanie Davis-Kahl, Illinois Wesleyan University, USA

Michael C. Seeborg, Illinois Wesleyan University, USA

\begin{abstract}
Although there are currently only a few undergraduate journals in economics, we expect their numbers to increase substantially in the future because of several developments: 1) research and writing activity is increasing in economics programs, 2) online publication is now more feasible and cost efficient than ever, and 3) students are increasingly aware of their on-line identity and desire to project a positive and professional image. Since increasing use of undergraduate journals might benefit a number of students, including potential article authors, article reviewers, and editors, there is a need to begin to assess the educational benefits of participation in journals. This paper reports results from a survey of reviewers who had reviewed articles for two undergraduate journals, The Park Place Economist and The Undergraduate Economic Review. The reviewers generally agreed that they received a range of benefits from the review process and nearly all agreed that reviewing had been a valuable use of their time. Several of the suggested benefits were positively correlated with measures of participation intensity. Nearly half the respondents thought the benefits would have been greater with more, not fewer, articles to review.
\end{abstract}

Keywords: Undergraduate Research; Undergraduate Journals; Active Learning; Assessment

\section{INTRODUCTION}

hile the use of undergraduate journals in economics is currently limited, a convergence of three trends
suggests an increase in their use. First, as documented by McGoldrick (2008), undergraduate research
and writing activity is increasing in economics programs. As more undergraduates are involved in research and writing, publication is a logical byproduct and is likely to become an increasingly popular co-curricular activity. Second, online publication is now more feasible and cost effective than ever. Third, students aware of their on-line identity may desire to project a positive and professional image through social networks and electronic communications (Martínez Alemán \& Wartman, 2009).

Given the expected increase in their use, it is important to begin exploring the benefits and feasibility of these undergraduate journals in economics. Drawing on our experience with two journals, The Park Place Economist and The Undergraduate Economic Review, this paper identifies some educational benefits of undergraduate journals and explores the feasibility of establishing new ones. We then present some preliminary assessment results for student article reviewers and finally, we offer suggestions for more extensive assessment in the future.

\section{POTENTIAL BENEFITS}

Research in the economic education arena has long recognized the benefits of engaging students in active learning, both in and out of the classroom. One favorable development is an apparent increase in writing within the curriculum. McGoldrick (2008) reports results from a survey completed by 254 economics departments indicating that about 70 percent of economics programs require writing of some sort. Our own experience shows that some of this writing is of very high quality and we have reason to think that there would be even more high quality work if students had more opportunities to share their work. 
DeLoach, Perry-Sizemore and Borg (2012), in a detailed exploration of effective undergraduate research programs in economics, reference a joint statement by the National Conferences on Undergraduate Research (NCUR) and the Council of Undergraduate Research (CUR) which outlines a four-step research process. The last step is for new scholars to share their discoveries with peers. McGoldrick (2007) makes a similar recommendation in her outline of ten key steps in an undergraduate research model based on Hansen's 2006 list of proficiencies. McGoldrick's final step is for students to present their research to peers and/or faculty. While McGoldrick probably had oral presentations in mind, we believe that presenting to peers through undergraduate publication also would serve this interest.

Undergraduate journals can be excellent complements to a department's capstone experience or other courses that require students to conduct original research (Carlson, et. al., 1998; and Seeborg, 2008). Students can benefit in several ways. First, by presenting them with examples of good undergraduate writing, we provide students with examples they can mimic. Such examples may have greater credibility than professional papers because they were written by peers. High quality student writing anchors the peer-review process at the upper end; if students' own drafts do not meet these standards, then the question is why, and what can be done to fix them. Second, students whose writing does meet high standards are rewarded with the chance to present their work in undergraduate journals. This should provide an incentive for students to work to improve their writing. Further, involving students in the peer review process can help to develop critical thinking skills as they evaluate other students' arguments, empirical models, and exposition. Finally, engaging students in establishing the criteria for reviewers to follow helps to develop a consistent, shared vision of a journal's purpose.

\section{FEASIBILITY OF ESTABLISHING AN UNDERGRADUATE ECONOMICS JOURNAL}

We describe our experience with undergraduate economics journals to establish that the creation of such a journal is certainly feasible. The Department of Economics at Illinois Wesleyan University (IWU) currently supports two undergraduate journals (Carlson, et. al, 1998 and Seeborg, 2008). The Park Place Economist (PPE), first published in 1993, is an annual in-house publication. It is run by IWU students and only publishes material authored by IWU students. The Undergraduate Economic Review (UER), first published in 2005, accepts submissions from undergraduate students from any university. The $P P E$ has both hard copy and electronic versions (http://digitalcommons.iwu.edu/parkplace/) while the UER is strictly online (http://digitalcommons.iwu.edu/uer/). Both journals fit the widely accepted definition of "open access" publications - "digital, online, free of charge, and free of most copyright and licensing restrictions." (Suber, 2012) Further, student authors retain the copyright to their work. A benefit of involvement with the journals is that both $P P E$ and $U E R$ staff learn about open access, copyright, author rights and the economics of scholarly publishing.

Both journals are under the general oversight of faculty advisors, with Robert Leekley overseeing the $P P E$ and Michael Seeborg and Stephanie Davis-Kahl overseeing the UER. The role of faculty advisors is intentionally limited to general oversight since we want student editors to be actively and meaningfully involved in running the journals. However, faculty advisors need to be very involved in the early stages of developing a new journal, especially in setting up the organizational structure and in making sure that editorial criteria for reviewing articles are sound and understood by the editorial staff and reviewers. The faculty advisors, in consultation with other department members, select a student Editor-in-Chief for each journal. Ideally these are students who have "come up through the ranks" as authors and/or reviewers. The Editor-in-Chief assigns submissions to reviewers who rate them according to established editorial criteria. Reviewers may also write critical evaluations and make recommendations to the Editor-in-Chief about whether to accept or reject submissions. The Editor-in-Chief makes the final decision.

The in-house PPE is designed to allow many IWU economics students the opportunity to be involved. In addition to submission and review of research papers, students are involved in writing columns about departmental events, alumni accomplishments and the plans of graduating seniors. The PPE has been an effective tool for connecting with alumni and many have indicated how they enjoy receiving the journal.

The UER, which accepts submissions world-wide, is evolving through a special collaboration between Illinois Wesleyan University economics faculty members and a librarian, Stephanie Davis-Kahl. Davis-Kahl has responsibility for Digital Commons @ IWU, the university's online archive, and coordinates publishing activities using the Berkeley Electronic Press (bepress) software platform. All correspondence between student editors, authors 
and reviewers moves through this framework using standard letters and forms which can be tailored to meet the journal's needs. This arrangement has eased the clerical burden of tracking articles and has allowed student editors to concentrate more on judging content and making editorial decisions.

Another advantage of using a publishing platform such as EdiKit from bepress or Open Journal Systems from the Public Knowledge Project is the ability to disseminate and share student work without restrictions, i.e., open access. Students' work is full-text searchable through search engines and on the journals' Digital Commons sites, and editors and advisors can glean information from download reports and Google Analytics data. For example, we learned that there were 5,363 full text downloads of articles published in the UER during October, 2012, and the number of downloads have been climbing steadily. We believe that usage statistics like these provide further incentives to students to do quality research and to student editors to take their editorial duties seriously.

We suspect that most departments that are considering an undergraduate journal will want to start with an in-house journal. We believe that such a journal is a very effective co-curricular activity that complements most economics major programs, especially those with a strong undergraduate research component. The startup costs can be quite low. All that is needed is a link on the departmental home page to an undergraduate journal page. The journal page would contain the name of the publication and a list of student editors and reviewers. It would also contain links to accepted student papers and to information about the journal and its evaluation criteria. Developing the intellectual infrastructure of the journal is a perfect opportunity to engage students in a discussion about evaluation criteria, goals of the journal, and the crucial role of the reviewer within the publication process.

In conclusion, our experience with The Park Place Economist and The Undergraduate Economic Review demonstrates the feasibility of establishing undergraduate economics journals. However, assessment of educational outcomes is more difficult. Do Editors-in-Chief improve their organizational and critical thinking skills? Do authors become better researchers and writers when they work toward publication? Do student reviewers benefit from the review process? The next section presents some assessment evidence on how reviewers benefit.

\section{ASSESSMENT}

Since undergraduate economics journals are still a rarity in economics, it is not surprising that very little serious work has been done to assess their effectiveness in promoting student learning. We describe our first tentative steps toward assessing the use of undergraduate journals and peer review in our curricular and co-curricular pedagogy. We recognize the limited nature of this assessment. The sample is necessarily small and non-random. For the most part, it consists just of students' perceptions. Still, it is a start.

Several groups of students likely have benefited from their experience with the journals and, thus, could be subjects of assessment. The Editors-in-Chief were intensively involved, like no one else, in all aspects of the journals. Benefits might easily have extended to the honing of their time-management and leadership skills. Authors of journal submissions may well have been influenced to improve their papers in the hopes of publishing them. Finally, article reviewers may have benefited from seeing and evaluating other students' research. Our first attempt at assessment targets the reviewers.

First, we describe an initial survey of students who had participated in reviewing articles for the UER and/or PPE in the 2011-2012 academic year. Next, we describe results of the survey and attempt to interpret patterns we see in the responses.

\section{Survey of Reviewers}

We constructed a survey instrument to be administered online. On April 19, 2012, we deployed the instrument to 43 students who had reviewed articles for either the UER or the PPE in the 2011-2012 academic year. We sent a follow-up reminder the next week and closed the survey on April 28, 1012. We received 24 (56\%) responses; however, only $17(40 \%)$ answered questions of substance. Our sample is 17. 
The $P P E$ reviewers included the editor-in-chief, various associate editors, and article editors who had probably invested a fair amount of effort in producing the volume, as well as proofreading editors, who probably had not. The UER reviewers included the editor-in-chief, associate editors, as well as students who reviewed one article as a class assignment. We suspect, though we do not know, that our sample response is somewhat biased in favor of those students with the greatest personal involvement with the journals. Results should be read with this probable bias in mind.

\section{RESULTS}

Table 1 presents the results for questions asking about the potential educational benefits of reviewing articles for the journals. At least $75 \%$ of respondents answered "Yes, definitely" or "Somewhat" to each suggested benefit and the remainder answered "not sure", "not really", or "not at all." Students clearly saw participation as a resume enhancer. More substantively, they thought they had been exposed to other models of research and inquiry, had learned about other areas of economics, and new applications of economic concepts, and had learned about the review and selection process in professional journals. They were less positive about finding a model for their own writing or further developing analytic thinking skills. All but one respondent answered "Yes, definitely" or "Somewhat" that reviewing for the journals had been a valuable use of his or her time.

Table 1: Potential Benefits And Costs Of Reviewing

\begin{tabular}{|c|c|c|c|c|c|c|}
\hline & $\begin{array}{c}\text { Yes, } \\
\text { Definitely }\end{array}$ & Somewhat & $\begin{array}{l}\text { Not } \\
\text { Sure }\end{array}$ & $\begin{array}{c}\text { Not } \\
\text { Really }\end{array}$ & $\begin{array}{c}\text { Not } \\
\text { At All }\end{array}$ & $\begin{array}{c}\text { Total } \\
\text { Responses }\end{array}$ \\
\hline $\begin{array}{l}\text { Exposed me to other models of research and } \\
\text { inquiry }\end{array}$ & 10 & 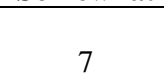 & 0 & 0 & 0 & 17 \\
\hline $\begin{array}{l}\text { Helped make me more aware of using data as } \\
\text { evidence in my own writing }\end{array}$ & 8 & 8 & 0 & 1 & 0 & 17 \\
\hline Offered me a model for my own writing in general & 5 & 7 & 2 & 2 & 0 & 16 \\
\hline Helped me further develop analytic thinking skills & 5 & 8 & 2 & 2 & 0 & 17 \\
\hline Helped me learn about other areas of economics & 9 & 4 & 1 & 2 & 0 & 16 \\
\hline $\begin{array}{l}\text { Helped me learn about new applications of } \\
\text { economic concepts }\end{array}$ & 11 & 4 & 0 & 2 & 0 & 17 \\
\hline $\begin{array}{l}\text { Improved my understanding of economics } \\
\text { concepts in general }\end{array}$ & 6 & 8 & 2 & 0 & 0 & 16 \\
\hline $\begin{array}{l}\text { Helped me learn the value of judging others' work } \\
\text { using specific criteria }\end{array}$ & 9 & 6 & 1 & 1 & 0 & 17 \\
\hline $\begin{array}{l}\text { Improved my understanding of how articles are } \\
\text { reviewed and selected in professional journals }\end{array}$ & 10 & 7 & 0 & 0 & 0 & 17 \\
\hline $\begin{array}{l}\text { Offered evidence of co-curricular activity on my } \\
\text { resume/portfolio }\end{array}$ & 13 & 3 & 0 & 1 & 0 & 17 \\
\hline $\begin{array}{l}\text { Reviewing submissions has been a valuable use of } \\
\text { my time }\end{array}$ & 11 & 5 & 0 & 1 & 0 & 17 \\
\hline
\end{tabular}

A separate question asked whether, through working on the $U E R$ and/or $P P E$, respondents had gained a better understanding of what Open Access publishing is. The results were not quite as strong, with just 63\% responding "Yes, definitely" or "Somewhat."

Finally, respondents were asked what would have made the reviewer experience better. Interestingly, eight respondents (47\%) would have liked more articles to review versus just one (6\%) who would have liked fewer. Others (35\% each) would have liked better instruction on how to review articles and would like those more closely matched to their interests and skills. 


\section{Interpretation}

A weakness in our survey was a dearth of measures to explain why students responded as they did. We conjecture that one answer is the intensity of their involvement in the review process. We proxy this in the four ways available in our survey - the number of articles reviewed for the $U E R$, the number of articles reviewed for the $P P E$, the number of articles reviewed for the two journals together, and the total time spent reviewing.

Table 2: Relationship Between Review Intensity And Benefits

\begin{tabular}{|c|c|c|c|c|c|}
\hline & & $\begin{array}{c}\text { \# UER } \\
\text { Articles } \\
\text { Reviewed } \\
\end{array}$ & \begin{tabular}{|c|}
$\# P P E$ \\
Articles \\
Reviewed \\
\end{tabular} & $\begin{array}{c}\begin{array}{c}\text { \# Combined } \\
\text { Reviewed }\end{array} \\
\end{array}$ & $\begin{array}{l}\text { Time Spent } \\
\text { Reviewing }\end{array}$ \\
\hline \multicolumn{6}{|c|}{ 1. Exposed me to other models of research and inquiry } \\
\hline & Pearson Correlation & 0.156 & 0.077 & 0.172 & 0.029 \\
\hline & Sig (2 tailed) & 0.550 & 0.770 & 0.509 & 0.913 \\
\hline & $\mathrm{N}$ & 17 & 17 & 17 & 17 \\
\hline \multicolumn{6}{|c|}{ 2. Helped make me more aware of using data as evidence in my writing } \\
\hline & Pearson Correlation & 0.000 & -0.026 & -0.018 & -0.083 \\
\hline & Sig (2 tailed) & 1.000 & 0.920 & 0.945 & 0.751 \\
\hline & $\mathrm{N}$ & 17 & 17 & 17 & 17 \\
\hline \multicolumn{6}{|c|}{ 3. Offered a model for my own writing in general } \\
\hline & Pearson Correlation & 0.245 & $0.476 *$ & $0.515 *$ & 0.399 \\
\hline & Sig (2 tailed) & 0.359 & 0.062 & 0.041 & 0.125 \\
\hline & $\mathrm{N}$ & 16 & 16 & 16 & 16 \\
\hline \multicolumn{6}{|c|}{ 4. Helped me further develop analytic skills } \\
\hline & Pearson Correlation & 0.286 & 0.110 & 0.295 & 0.011 \\
\hline & Sig (2 tailed) & 0.265 & 0.674 & 0.250 & 0.966 \\
\hline & $\mathrm{N}$ & 17 & 17 & 17 & 17 \\
\hline \multicolumn{6}{|c|}{ 5. Helped me learn about other areas of economics } \\
\hline & Pearson Correlation & 0.223 & 0.397 & $0.455 *$ & -0.045 \\
\hline & Sig (2 tailed) & 0.406 & 0.128 & 0.077 & 0.869 \\
\hline & $\mathrm{N}$ & 16 & 16 & 16 & 16 \\
\hline \multicolumn{6}{|c|}{ 6. Helped me learn about new applications of economic concepts } \\
\hline & Pearson Correlation & 0.197 & $0.489 * *$ & $0.486 *$ & 0.047 \\
\hline & Sig (2 tailed) & 0.449 & 0.047 & 0.048 & 0.858 \\
\hline & $\mathrm{N}$ & 17 & 17 & 17 & 17 \\
\hline \multicolumn{6}{|c|}{ 7. Improved my understanding of economics concepts in general } \\
\hline & Pearson Correlation & 0.000 & 0.122 & 0.082 & 0.000 \\
\hline & Sig (2 tailed) & 1.000 & 0.653 & 0.763 & 1.000 \\
\hline & $\mathrm{N}$ & 16 & 16 & 16 & 16 \\
\hline \multicolumn{6}{|c|}{ 8. Helped me learn the value of judging others' work using specific criteria } \\
\hline & Pearson Correlation & -0.138 & -0.024 & -0.122 & -0.147 \\
\hline & Sig (2 tailed) & 0.598 & 0.927 & 0.641 & 0.573 \\
\hline & $\mathrm{N}$ & 17 & 17 & 17 & 17 \\
\hline \multicolumn{6}{|c|}{ 9. Improve my understanding of how articles are reviewed/selected in professional journals } \\
\hline & Pearson Correlation & -0.078 & -0.184 & -0.186 & 0.029 \\
\hline & Sig (2 tailed) & 0.766 & 0.479 & 0.474 & 0.913 \\
\hline & $\mathrm{N}$ & 17 & 17 & 17 & 17 \\
\hline \multicolumn{6}{|c|}{ 10. Offered evidence of co-curricular activity on my resume/portfolio } \\
\hline & Pearson Correlation & -0.201 & 0.419* & 0.134 & -0.074 \\
\hline & Sig (2 tailed) & 0.439 & 0.094 & 0.609 & 0.778 \\
\hline & $\mathrm{N}$ & 17 & 17 & 17 & 17 \\
\hline
\end{tabular}

*Significant at the 0.10 level

**Significant at the 0.05 level

Table 2 presents simple correlations between each of these measures and the ten proposed benefits. Very few are statistically significant-not surprisingly given our small sample. The number of $U E R$ articles reviewed and the time spent reviewing have consistently insignificant effects. However, the number of PPE articles reviewed and the 
number of articles combined appear related to several proposed benefits that seem sensible. Those who had reviewed more articles tended more to see a model for their own writing. Those who had reviewed more articles tended more to experience the benefits of learning about other areas of economics, as well as new applications of economic concepts. Even the divergent results for resume enhancement make some sense. The PPE is entirely co-curricular; participants are likely to think that participation is something "extra." Indeed, the Editor-in-Chief used the resume argument in her class visits to recruit participants. The UER is primarily co-curricular as well, but is sometimes used in class assignments. Participants who review an article as a class assignment may be less likely to think of it as something extra.

Table 3 offers simple correlations between each of the intensity measures (except time spent reviewing) and the ways in which reviewers' experiences could have been better. Again, there are very few statistically significant results. However, there are two - this time for the number of $U E R$ articles reviewed. The negative coefficient for wanting more articles makes sense. Those who had few articles to review were the most likely to have wanted more. It also appears that those who had more articles to review were more likely to find mismatches with their interests.

Table 3: My Experience As A Reviewer Would Have Been Better If --

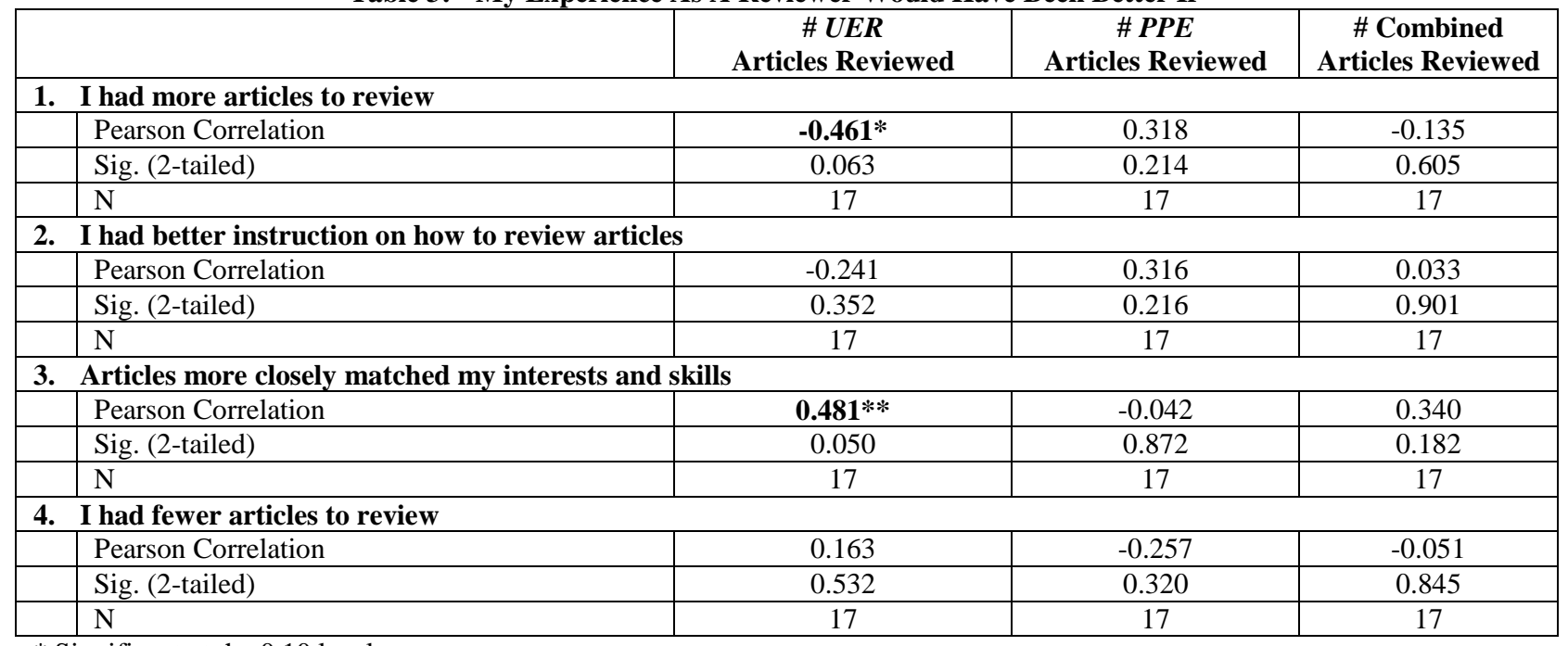

* Significant at the 0.10 level

**Significant at the 0.05 level

\section{NEXT STEPS}

Assessment of reviewer experience will continue. We are currently planning to link such assessment more directly to the review process by having reviewers respond to a questionnaire about the review experience immediately after they complete the review. Since they have just completed the review process, they would not need to rely on their memory of an experience that was not of long duration and could have occurred months earlier. This should give us better input into how students perceive the review experience as they are completing it.

Getting accurate assessment data on the educational outcomes for authors is more problematic. It is unlikely that authors would negatively assess their experience if the article is currently under review. But, waiting until after the submission is either accepted or rejected could also cause obvious biases in responses. Still, it is interesting to know how authors benefit. For some, perhaps the possibility of publishing results in a better product. For others, the submission of the article may be just an attempt to validate an already very good project.

Finally, the Editors-in-Chief should be interviewed during the academic year to assess their experience. It would be particularly interesting to determine the perceived benefits and costs of their involvement. They probably would respond honestly to questions concerning what they are sacrificing to take on this time-consuming leadership role and how they might be benefitting. 


\section{CONCLUSIONS}

While the use of undergraduate journals in economics is somewhat limited at present, a convergence of trends suggests an increase in their use. First, as documented by McGoldrick (2008), research and writing activity is increasing in economics programs. Second, online publication is now more feasible and cost efficient than ever. Third, students are increasingly aware of their on-line identity and desire to project a positive and professional image (Martínez Alemán, \& Wartman, 2009).

Increasing use of undergraduate journals is likely to benefit a number of groups (Carlson, et. al., 1998; Seeborg, 2008). Outstanding undergraduate research publications can provide excellent models to student researchers as they strive to produce good work. Reviewers may benefit from evaluating others' work for possible publication. Authors may be motivated to do better work for the opportunity to share their work with a wider audience. Editors-in-Chief may benefit from the honing of their leadership skills.

This paper provides some assessment evidence that our sample of student reviewers benefit from participation in the review process. While the numbers involved were small, respondents generally agreed that they benefitted in a number of ways (Table 1), and all but one respondent agreed that reviewing had been a valuable use of time. Finally, those who had participated more intensely in the review process perceived greater benefits. Future research should continue to assess reviewer experiences with larger samples of respondents and also should attempt to assess the impact of undergraduate journals on the educational outcomes of student authors and editors in chief.

\section{AUTHOR INFORMATION}

Robert M. Leekley is an Associate Professor of Economics at Illinois Wesleyan University (IWU). His research is mainly in empirical public economics, where he has had a longstanding interest in the economics of education. Leekley, who is the author of a recently published statistics textbook, teaches statistics, intermediate microeconomics and applied econometrics. The econometrics class is noteworthy in that students are required to conduct original research projects. He has been involved in faculty governance, serving as department chair, and on many university committees. He also is faculty advisor to IWU's undergraduate economics journal, The Park Place Economist. E-mail: bleekley@iwu.edu

Stephanie Davis-Kahl is the Scholarly Communications Librarian and Associate Professor at Illinois Wesleyan University. She provides leadership for development of scholarly communication programs and initiatives at Illinois Wesleyan. She works to collect and disseminate student and faculty publications using Digital Commons @ IWU. As the Managing Faculty Co-Editor of the Undergraduate Economic Review, she works closely with students on all aspects of the publishing process. She also provides research consultation, collection development and instruction services to a number of departments. She is Past Chair of the Education and Behavioral Sciences Section of the Association for College and Research Libraries. E-mail: sdaviska@iwu.edu

Michael C. Seeborg, the Eckley Professor of Economics at Illinois Wesleyan University (IWU), is the author of numerous articles in labor economics. His research interests are varied and include work on the economics of immigration, poverty, and sports. He teaches many courses that focus on economic research, including the economics capstone senior project course, a May Term course on applied research in labor economics, and a writing intensive course first year students. He helped establish two student undergraduate economics journals and is currently Managing Faculty Co-Editor of the Undergraduate Economic Review. E-mail: mseeborg@iwu.edu

\section{REFERENCES}

1. Carlson, J.L, Chizmar, J.F., Seeborg, M.C. and Walbert, M.S. (1998). Using Undergraduate writing in economics. The Journal of Economics 24 (2): 77-86.

2. DeLoach, S.B., Pery-Sizemore, E. and Borg, M. 2012. Creating quality undergraduate research programs in economics: how, when, where and why. The American Economist 57 (1): 96-110.

3. Martínez Alemán, A. M. and Wartman, K. L. 2009. Online social networking on campus: Understanding what matters in student culture. New York: Routledge.

2013 The Clute Institute http://www.cluteinstitute.com/ 
4. McGoldrick, K., 2008. Writing requirements and economic research opportunities in the undergraduate curriculum: Results from a survey of departmental practices. Journal of Economic Education 39 (Summer): 287-96.

5. McGoldrick, K., 2007. Undergraduate research in economics. Handbook for Economics Lecturers. http://www.economicsnetwork.ac.uk/handbook/ugresearch/

6. Seeborg, M., 2008. Achieving proficiencies in economics capstone courses," Journal of College Teaching and Learning 5 (2): 61-73.

7. Suber, P., 2012. Open Access Overview (Website). http://www.earlham.edu/ peters/fos/overview.htm 